ISSUE BRIEF

\title{
Issues Facing Major Research Universities at a Time of Stress AND Opportunity
}

\author{
April 12, 2016
}

William G. Bowen
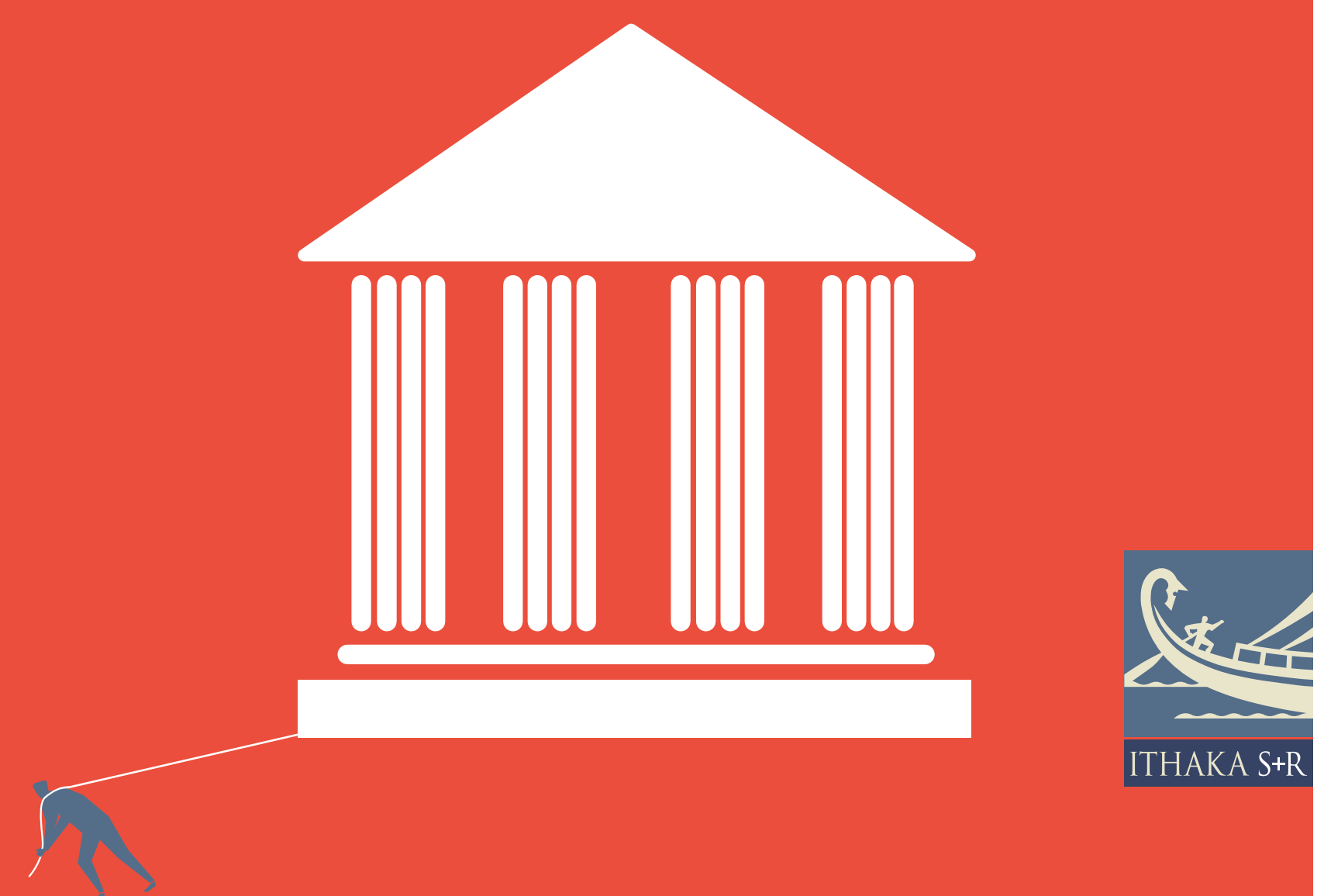


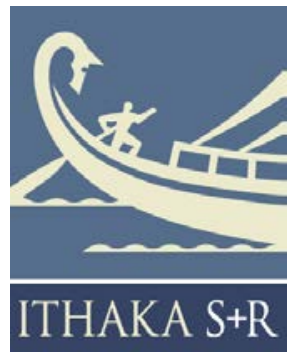

Ithaka $\mathrm{S}+\mathrm{R}$ is a strategic consulting and research service provided by ITHAKA, a not-for-profit organization dedicated to helping the academic community use digital technologies to preserve the scholarly record and to advance research and teaching in sustainable ways. Ithaka $\mathrm{S}+\mathrm{R}$ focuses on the transformation of scholarship and teaching in an online environment, with the goal of identifying the critical issues facing our community and acting as a catalyst for change. J STOR, a research and learning platform, and Portico, a digital preservation service, are also part of ITHAKA.

Copyright 2016 ITHAKA. This work is licensed under a Creative Commons Attribution-NonCommercial 4.0 International License. To view a copy of the license, please see http://creativecommons.org/licenses/by-nc/4.0/.

ITHAKA is interested in disseminating this brief as widely as possible. Please contact us with any questions about using the report: research@ithaka.org. 
This Issue Brief presents the lightly edited text of William G. Bowen's keynote address at the Rutgers University 250"t Anniversary Presidential Symposium on Higher Education, delivered in New Brunswick, NJ , on April 7, 2016.

I would like to begin by acknowledging some of my many debts to Rutgers. My wife and I both have Rutgers degrees, hers an earned Master's Degree and mine one of the "unearned" kind. Beyond that, as a close neighbor of Rutgers for many years, living right "down the road" as it were, I have watched the evolution of this great institution with intense interest.

The historical connections between Rutgers and Princeton, dating back to colonial days, are legendary. Over the years, Rutgers has made major contributions. Among her many distinguished recipients of undergraduate degrees, I note Paul Robeson and the economist Milton Friedman — a sometime antagonist of mine! Among the $\mathrm{PhD}$ recipients is William "Brit" Kirwan in mathematics, a distinguished leader of public higher education, a close friend, and a current collaborator. I could go on, but the list would quickly become overwhelming. On the research front, I would mention only that streptomycin was first isolated in a Rutgers laboratory in the 1940s.

\section{Framing the Discussion}

Aware as we are of a truly glorious history, we should look ahead. As the title of my talk indicates, this is without question a time for great public universities such as Rutgers, of both stress and opportunity. ${ }^{1}$ The stress, you know all too well, derives from, first of all, shrinking resources, especially when measured on a per student basis. In New J ersey, public higher education enrollment increased by 11 percent between 2009 and 2014, while educational appropriations per FTE fell by 23.4 percent. This is an unwelcome but inescapable historical fact of recent days. At the same time, there are also rising expectations as to the contributions that institutions like Rutgers can and should make to solving pressing national needs. These needs, which Mike McPherson and I describe in a just-published book called Lesson Plan: An Agenda for Change in American Higher Education, include higher completion rates for undergraduates coupled with shorter time-to-degree; a marked reduction in disparities in educational outcomes associated with socioeconomic status; and greater success in controlling increases in costs while maintaining the quality of education. The country also needs to count on leading

\footnotetext{
${ }^{1}$ For help in the preparation of this talk I wish to thank my colleagues, Johanna Brownell and Lisa Krueger, as well as Professor Mark R. Killingsworth of Rutgers University. Also, I have borrowed liberally from two books that I have written recently with (respectively) Eugene M. Tobin and Michael S. McPherson. Of course, I am solely responsible for all errors and confusions that remain.
} 
graduate programs to continue to provide a fresh generation of intellectual leadership and ever-new additions to the stock of knowledge-as Rutgers has long done.

\section{This well-documented season of discontent ... has been fueled in part by the increasing gaps in society between the "haves" and the "have-nots" - gaps which are surely responsible, along with partisan rancor, for the raw anger so evident in today's political campaigns.}

Moreover, all of this needs to be accomplished while stopping the pernicious erosion of trust in higher education. This well-documented season of discontent, following a long period in which higher education was highly regarded, has been fueled in part by the increasing gaps in society between the "haves" and the "have-nots" - gaps which are surely responsible, along with partisan rancor, for the raw anger so evident in today's political campaigns. I resist the temptation to say more on this inflammatory topic.

It is also true that many potential friends of higher education are appalled by the distortions in values and priorities that are driven, increasingly I fear, by the overly zealous pursuit of glories on the intercollegiate playing fields of what are meant to be principled centers of learning - not purveyors of mass entertainment, and certainly not academic hideaways for both recruited athletes and complicit coaches. Let me not be coy: Rutgers appears to have had some experience with these problems - in keeping, to be sure, with many other universities. And the super-privileged places like Princeton, Harvard, and Stanford are hardly without their own challenges in this treacherous terrain. Let me not be misunderstood. I am a great sports fan, and I believe strongly in intercollegiate sports when integrated within a sound educational program. I am a strong proponent of the virtues of competition. After attempting to explain to my son the values of participation (whatever the outcome), I can still hear him replying: "But dad, the fun is in the winning." Fine, but the pursuit of winning should be bounded by the right set of values and not driven by the incentives that seem to have overtaken much of the enterprise.

These stresses notwithstanding, this is also a time of great opportunity for public universities since they alone have the capacity to address many of these needs. The truly heavy-lifting has to be done by places like Rutgers, not by their more privileged cousins. And there are steps that can be taken to make progress on many fronts. Progress will, 
however, require candid stock-taking of where we are, readiness to attack major issues, and a willingness to adjust some (certainly not all) modes of decision-making that date back to the $19^{\text {th }}$ century. I remain a strong advocate of shared governance, but I believe that hallowed phrase needs to be re-thought in some ways and not misused to prevent needed changes in the way universities operate today.

Let me now discuss some specific issues before us. I focus on just five: presidential leadership; growing disparities in educational outcomes related to socioeconomic status; educational costs and teaching methods involving technology; treatment of a nascent teaching corps; and principles of shared governance. I will include some historical references in this litany.

\section{Presidential Leadership}

In the spirit of "taking it from the top," I begin with presidential leadership. From its earliest days, American higher education, unlike higher education in much of the rest of the world, was notable for vesting much authority - and responsibility - in strong presidents. This is, in my view, all to the good. And, having "been there," you will not be surprised to hear that I agree strongly with something Clark Kerr said more than a halfcentury ago: we should stop denigrating leadership, encourage risk-taking (alongside accountability), and build up rather than tear down the capacity of able leaders to, in fact, lead.

Putting in place, and retaining, able presidential leadership is no simple task. It requires, of course, both identifying the right person and persuading him/ her to accept a truly demanding position - whether more or less demanding today than in days gone by is a nice question to which the answer will vary depending on institutional circumstances.

In any case, there is no substitute for the active engagement of trustee-led search committees in identifying and recruiting the right leader. The board as a whole must then be responsible for actually selecting and supporting the best candidate. This is certainly not to deny that faculty should be heavily involved. On the contrary, strong faculty involvement is today a sine qua non, as it was not in early days. Faculty are likely to have a keen sense of what an institution needs most in a new leader; they will be able to discern whether particular candidates have the requisite sensitivities to lead an academic enterprise; and, finally, faculty can be extremely helpful in persuading the right candidate to accept a genuinely tough job. In seeking to define the faculty role in this process, we should recognize that there is no one formula that will work in all situations. Ideally, the "right" faculty will be chosen to participate actively in the search for a new leader and will accept (cheerfully) a role as trusted advisors to the board. Faculty can be, 
and should be, highly influential without expecting to have the final "say" in the process. In almost all situations, the best candidate will want to be sure that he/ she has the support of the faculty as well as of the board. To inject a personal note, it was a trusted faculty colleague at Princeton who persuaded me, at an absurdly young age, to take on a presidency for which I was unsure I was suited. And it was faculty who propped me up at critical moments.

Outside search firms can be very helpful, but in limited ways. In particular, they can be invaluable in identifying potential candidates who might otherwise have been overlooked. But I do not think that representatives of search firms should be expected to ascertain the interest of promising candidates; these firms may have agendas of their own and, in any case, are not likely to be seen by the most attractive prospects as the face of the institution. I was involved in a specific situation in which a top candidate told a search firm that he was not interested in being considered when in fact a later conversation with the chairman of the board led to a different conclusion - and to the individual's eventual election as president.

\section{Disparities in Educational Outcomes, "Free Tuition," and Financial Aid Policies}

This nest of issues is, to my way of thinking, enormously important-not only to higher education but to society at large. It is more important today than ever before, in part because of the historically high premium associated with college completion. This is a knowledge-driven age. And all of us who believe strongly in social mobility should be alarmed by the fact that 60 percent of students from families in the top SES quartile earn BAs (or higher degrees) as compared with just 14 percent of students from the bottom SES quartile and 29 percent of students from families in the middle two SES quartiles. ${ }^{2}$ Nor can this frightening disparity be explained away by referencing differences in expectations or differences in preparation. For example, it is sobering to note that lowSES students who placed in the highest math achievement quartile were far less likely to earn at least a BA than were high-SES students who also placed in the highest math quartile (41 percent vs. 74 percent); moreover, 21 percent of high-SES students who placed in the lowest math proficiency quartile earned at least a BA (as compared with 5 percent of low-SES students). As one scholar opined: “Put bluntly, class trumps ability

\footnotetext{
${ }^{2}$ See National Center for Educational Statistics, “Education Longitudinal Study of 2002," (ELS: 2002), Base Year and Third Follow-up. See also Institute of Education Sciences, Digest of Education Statistics, 2014, (Washington, DC), table 104.91, available at http://nces.ed.gov/programs/digest/2014menu tables.asp.
} 
when it comes to college graduation." 3 Furthermore, the limited evidence that is available gives us no reason to believe that these disparities are diminishing. This is a terribly troubling phenomenon in search of an explanation.

More money would surely help address gaps in outcomes, but it is necessary to be careful in choosing among ways of addressing affordability issues. Sloganeering needs to be kept in its place. One recurring proposal is to make public colleges "free" for all students. There are at least four reasons for being highly skeptical about this idea. First, it would be enormously expensive - and I see no reason to believe that states would appropriate the resources required to cover essential educational costs. On the contrary, it is all too evident that pressures to reduce state support are stronger than ever. Second, "free" is not the same as "affordable." Third, such a policy would fly in the face of widely stated desires to address equity issues. The main beneficiaries of "free tuition" would be the children of reasonably affluent families who attend public universities and certainly can afford to share in the costs of educating children who, on average, benefit substantially from a college education. Do we really believe that the children of Donald Trump should be absolved from sharing in the costs of attending a fine public institution -or, the children of a Bernie Sanders, for that matter? Fourth, there is abundant evidence that wise targeting of limited resources on students who have demonstrated need is far more effective than "free tuition" in increasing overall completion rates and reducing disparities in outcomes.

This last point brings us directly to another sensitive but important issue: the wisdom of providing "merit aid" to students without demonstrated need. There is a disturbing trend for public universities, as well as private colleges and universities, to use merit aid to bid for students of promise, including students from relatively affluent backgrounds. Recently, 25 percent of institutional aid provided by public universities was awarded without reference to need. There is evidence that "free education" lengthens time-todegree, since the incentive to complete one's studies expeditiously is reduced.

\section{Scarce dollars spent on merit aid could do much more good if targeted on needy students.}

\footnotetext{
${ }^{3}$ These are Susan Dynarski's words in commenting on the ELS: 2002 study. See her column, "For the Poor, the Graduation Gap is Even Wider than the Enrollment Gap," New York Times, Upshot, June 2, 2015. http://www.nytimes.com/2015/06/02/upshot/for-the-poor-the-graduation-gap-is-even-wider-than-the-enrollmentgap.html? $r=0$.
} 
There is another point that is even more powerful. The able (and courageous) chancellor of the University of Wisconsin, Rebecca Blank, from whom we have just heard, has reluctantly concluded that she has no choice but to join the party (lest she lose increasing numbers of able students to neighboring public institutions that offer generous merit aid) - even though she has agreed that this effort to redistribute able students from one place to another makes little sense from a national perspective. ${ }^{4}$ Scarce dollars spent on merit aid could do much more good if targeted on needy students.

Implicit in what I have just said is a broader issue that is quite profound. For some time now, universities, and particularly the publics but many privates as well, have been engaged in an arms race on several fronts-competing to enroll top students, spending more on sports and on ancillary facilities (fancy gyms, exotic dining options, and the like). What students of game theory call the "prisoner's dilemma" applies: a single institution doesn't dare hold off on these kinds of expenditures because if they do, rivals will gain a huge competitive advantage. So each institution is tempted (driven really) to spend scarce funds on activities that have less and less to do with real education. Most everyone becomes worse off and the cost of education for students in general goes up. This is not a problem any one institution can solve on its own. What is required is a "non-proliferation" treaty that in turn depends on truly strong - and collaborativeleadership.

\section{Educational Costs, Teaching Methods, and Technology}

Important as it is to improve educational outcomes - and it is not just very important, it is essential-this must be accomplished without unduly increasing educational costs and, ideally, restraining the rate of increase in costs for institutions as well as for individuals. To be sure, the rate of increase in actual ("net") college costs is often exaggerated, and too much attention is paid to the "sticker prices" of elite private universities that enroll tiny shares of the student population. Loans incurred by typical students are also

\footnotetext{
${ }^{4}$ Blank has said, "It worries me a great deal, the type of merit aid I see being offered to top students from Wisconsin ... As far as I'm concerned -- I'm an economist -- that's a real waste of where we should be spending our money in higher ed. But I've got to keep some of those top students in Wisconsin... The students who are going to go to Harvard, I may not be able to keep them at Wisconsin if that's the sort of experience that they want. But I have a lot of top students who get recruited away [by] lowa and Indiana and Illinois and Minnesota. And I'll say this, we're a better school than them. They should be coming to us and not going out of state." See Kellie Woodhouse, "Playing the Aid Game," Inside Higher Ed, December 18, 2015. https://www.insidehighered.com/news/2015/12/18/university-wisconsin-ups-its-merit-aid-effort-bettercompete-peers.
} 
exaggerated by many. Moreover, leaders of higher education suffer from ill-founded and unsupported charges of "administrative bloat."5

\section{Academia has to consider, responsibly, how to manage trade-offs and, especially, how to take advantage of new technologies to teach foundational courses in gateway fields like beginning mathematics more effectively.}

Still there is no denying that for many students (and their families) the costs of education are a real problem. Nor is there any denying the existence in academia of a deep-seated aversion to considering ways of controlling costs, and especially instructional costs. As Clark Kerr noted years ago: "The call for effectiveness in the use of resources will be perceived by many inside the university world as the best current definition of evil." 6 This historically-rooted mindset has to change. Academia has to consider, responsibly, how to manage trade-offs and, especially, how to take advantage of new technologies to teach foundational courses in gateway fields like beginning mathematics more effectively.

Nationally, one of the biggest barriers to raising completion rates, especially for students from modest circumstances, is the failure of many well-motivated students to pass gateway courses in various branches of beginning mathematics. ${ }^{7}$ As Anthony Bryk,

\footnotetext{
${ }^{5}$ See William G. Bowen and Michael S. McPherson, Lesson Plan: An Agenda for Change in American Higher Education, Princeton University Press, Princeton, NJ, 2016, pp. 106-110.

${ }^{6}$ See Clark Kerr, The Uses of the University, $4^{\text {th }}$ ed. (the Godkin Lectures on the Essentials of Free Government and the Duties of the Citizen), Cambridge, MA: Harvard University Press, 1995, p. 181.

${ }^{7}$ As noted in the recent PCAST report "Engage to Excel," mathematics is seen as the number one barrier to college completion at a time when the nation needs many more mathematics majors, non-majors with more extensive and deeper mathematics preparation, and STEM majors who are better prepared for the mathematically intensive aspects of life sciences, social sciences, engineering, information technology, business, and security. See "Transforming PostSecondary Education in Mathematics - Report of a Meeting," University of Texas at Austin, June 20-22, 2014. https://d3n8a8pro7vhmx.cloudfront.net/math/pages/47/attachments/original/1415904260/TPSE Report pages web.pdf?1 $\underline{415904260}$
} 
president of the Carnegie Foundation for the Advancement of Teaching has put it: "developmental mathematics is where aspirations go to die." 8

Many efforts have been made, and more are underway, to address this critically important problem. I am, by nature, an incrementalist, and I applaud these projects. They can make a real difference. To its great credit, Rutgers has been active in this area and time precludes me from doing more than mentioning Rutgers' "Center for Online and Hybrid Learning and Instructional Technologies"; Rutgers also offers some fully online degrees.

But sometimes incrementalists can be ambitious and even, on occasion, advocate a "swinging for the fences" mode of attack (especially at the start of the baseball season). That is my posture. Having been skeptical for years that investing in technology has real promise in improving teaching methods at reasonable cost, I am now a convert-and an advocate of efforts that reach well beyond any single campus. I am not talking about MOOCs, useful as they are in increasing access to knowledge to individuals (most often, however, those with some prior training, not neophytes). But, with the best will in the world, MOOCs do not address the basic needs of mainstream public universities.

Rather, I believe that it is increasingly sophisticated forms of adaptive learning that have the real potential, especially when used in a hybrid mode that marries these approaches to some face-to-face contact. In essence, adaptive learning uses machine-guided methods of teaching basic concepts by means of feedback loops that provide timely hints to students and valuable data to teachers. ${ }^{9}$ This approach makes great sense when considering how best to teach some kinds of foundational courses in fields such as

\footnotetext{
${ }^{8}$ See Gay M. Clyburn, "Improving on the American Dream: Mathematics Pathways to Student Success," Change: The Magazine of Higher Learning," September-October, 2013, p. 17.

http://www.changemag.org/Archives/Back\%20lssues/2013/September-October\%202013/american-dream-full.html Of course, we all recognize that pre-college education today produces too many students who are not really ready for serious college work. In the longer run, our country simply must do a better job of preparing all of our students, including especially those from disadvantaged backgrounds, to have the opportunity to benefit from at least some kind of postsecondary experience. But, we have two hands. Important as it is to work on pre-collegiate problems (and some of the ways of improving college teaching, such as the proposed math program, may well help at the pre-college level as well), we cannot wait for some "revolution" at the pre-college level to solve present-day problems. We must all do all that we can to help those now graduating from high school to take full advantage of post-secondary opportunities of various kinds.

${ }^{9}$ A Tyton Partners report defines adaptive learning as "a more personalized, technology-enabled, and data-driven approach to learning that has the potential to deepen student engagement with learning materials, customize student's pathways through curriculum, and permit instructors to use class time in more focused and productive ways. In this fashion, adaptive learning promises to make a significant contribution to improving retention, measuring student learning, aiding the achievement of better outcomes, and improving pedagogy." They add, "If adaptive learning solutions are implemented at scale, then they have the potential - at least theoretically - to produce a higher-quality learning experience (as measured by student engagement, persistence, and outcomes) at potentially reduced cost by making high-quality instruction more scalable," Tyton Partners, Learning to Adapt: A Case for Accelerating Adaptive Learning in Higher Education, 4-5, http://tytonpartners.com/library/accelerating-adaptive-learning-in-higher-education/.
} 
mathematics and statistics to large numbers of students. Distinctions are crucial here. I am talking about subjects based on widely agreed propositions (what is a "t-test"?)—not the Arab-Israeli conflict! In choosing pedagogies, we have to avoid one-size-fits-all thinking.

One reason for guarded optimism is that there is evidence of some success with even primitive adaptive learning approaches. The most persuasive evidence is from a rigorous study my colleagues and I conducted of a hybrid statistics course which used Carnegie Mellon University's Open Learning Initiative machine-guided instruction software plus one face-to-face meeting a week. Colleagues and I carried out this study on six public university campuses that used randomized assignment of students to either a traditional version of the course or the hybrid model in order to control for selection effects. Findings were remarkably consistent across campuses. An adaptive learning structure, with multiple feedback loops, was found to yield essentially the same learning outcomes with much less face-to-face staff time and less time invested in the course by students. Another key finding was that an important sub-set of students, those who were relatively less prepared academically, did as well with the adaptive learning model as did their better-prepared classmates. ${ }^{10}$

To be sure, adaptive learning models can be, and are being, improved significantly by organizations such as Acrobatiq (a for-profit spin-off from Carnegie Mellon). A key question right now is whether we can assemble both the institutional partners and the resources needed to test the effectiveness of an improved adaptive learning platform that could scale up and yield highly cost-effective modes of teaching some kinds of basic content. This is a challenge worthy of the most forward-looking public universities, working in collaboration with both for-profit entities and their non-profit cousins (as well as with governmental agencies).

\footnotetext{
${ }^{10}$ For a full description of the study, see William G. Bowen, et al, "Interactive Learning Online at Public Universities: Evidence from Randomized Trials," Ithaka S+R, May 22, 2012, http://www.sr.ithaka.org/publications/interactive-learningonline-at-public-universities-evidence-from-randomized-trials/.
} 


\section{Rationalizing Staffing Patterns: Supporting a Teaching Corps}

Here is another noteworthy historical fact. Over the last 40 years or so, there has been a dramatic shift in the mix of faculty-from tenure-track to "conditional," "adjunct," or whatever word one wants to use to describe the variety of teaching staff that comprise the non-tenure track (NTT) faculty. In 1969, tenured and tenure-track faculty accounted for over three-quarters of all faculty; in 2009, tenured and tenure-track faculty accounted for just one-third of all faculty. ${ }^{11}$ At the risk of aggravating (yet again!) friends in the academic world, let me suggest that this shift is the unavoidable, and irreversible, consequence of unremitting cost pressures on higher education combined with trends in doctoral output. Technological advances also play a part in this process but, to date, a minor part.

On the demand side of the equation, many institutions have felt the need to curb increases in staffing costs, and NTT faculty are of course much less expensive than tenure-track faculty: they are less well paid, they are asked to teach more hours, their performance can be assessed with less controversy than the performance of tenure-track faculty, and they can be released if need be. ${ }^{12}$ To be sure, the country requires a heavy investment in top-level training in scholarship for the next generation of leaders of the scholarly enterprise - including, of course, those at Rutgers. In addition, a certain amount of attention to scholarship can be justified for all teaching staff as a form of professional development, but this need not be either extensive or expensive.

On the supply side, Mike McPherson and Charles Kurose of the Spencer Foundation have demonstrated that by the mid-1980s, "growth in the number of tenure-track faculty was only enough to absorb 10 to 16 percent of the $\mathrm{PhDs}$ produced." 13 A consequence is that the large number of aspiring faculty who cannot find tenure-track positions has provided a pool of potential teachers, many of whom prefer NTT positions to no place in academia at all.

\footnotetext{
${ }^{11}$ See William G. Bowen and Eugene M. Tobin, Locus of Authority: The Evolution of Faculty Roles in the Governance of Higher Education, Princeton University Press, 2016, for documentation of this shift and a fuller discussion of the reasons for it.

${ }^{12}$ Another factor, still in its early stages, is the "unbundling" of some teaching functions as a result of technological advances. "Unbundling" reduces the need for faculty to manage all aspects of a course. See William G. Bowen, "Academia Online: Musings (Some Unconventional)," Stafford Little Lecture, Princeton University, October 14, 2013.

${ }^{13}$ Michael McPherson and Charles Kurose, "Imbalance in Faculty Labor Markets," unpublished memo, September 23, 2014.
} 
It does no good to bemoan this shift, as a number of people insist on doing. ${ }^{14}$ The underlying market forces are not to be denied, and people should recognize candidly that the use of NTT faculty is often justified. There are, to be sure, pronounced differences in the case for using NTT faculty in some institutions and some settings as opposed to others. The wealthiest, most selective, and most privileged places will continue to make only limited use of this set of people, whereas the far larger number of mainstream public and private places will make more use of them. We should simply accept this situation as reality. Each institution has to do what it can afford and what is consistent with its sense of its own character and mission.

Rather than yearn for a return to an alleged "golden age" that is not achievable, it is far wiser for higher education to make the best accommodation it can to the shift in faculty mix that has transpired and find ways to make effective use of the still-growing ranks of NTT faculty. There is growing evidence that NTT faculty, when properly chosen, supported, and treated, can be highly effective teachers, especially of basic "foundational" courses. ${ }^{15}$ Putting aside any general presumption that tenure-track faculty must be the best teachers (which may be justified when it comes to teaching students how to do research, but not otherwise), it is hardly surprising that in at least some situations NTT faculty have been found to be more effective than their tenured counterparts - and especially effective with disadvantaged students. After all, there are surely "master teachers," who are primarily interested in teaching.

I am persuaded that higher education should professionalize the "teaching corps" much as many universities professionalized research staff following World War II and the explosive growth of sponsored research that accompanied it. In the immediate postwar years, it became evident that the substantial numbers of highly qualified scientists needed for large-scale research projects could not possibly be accommodated within the regular teaching faculty even though they were indispensable; still, they required status and appropriate conditions of employment. Today there are signs that more and more universities are recognizing the need to regularize conditions of employment for a

\footnotetext{
${ }^{14}$ See for example the proposal by Bernie Sanders to require institutions to retain a certain ratio of tenured to NTT faculty - an idea that ignores entirely the realities of the situation. According to Sanders, "States would have to promise that, within five years, 'not less than 75 percent of instruction at public institutions of higher education in the State is provided by tenured or tenure-track faculty." See Kevin Carey, "Bernie Sanders's Charming, Perfectly Awful Plan to Save Higher Education," Chronicle of Higher Education, July 6, 2015. http://chronicle.com/article/Bernie-SanderssCharming/231387

${ }^{15}$ Perhaps the best known study to reach this conclusion is the one by David Figlio and his colleagues at Northwestern. (David N. Figlio, Morton O. Schapiro, and Kevin B. Soter, "Are Tenure Track Professors Better Teachers?" NBER Working Paper 19406, September 2013, revised August 28, 2014, www.nber.org/papers/19406.
} 
professional "teaching corps." Northwestern, Michigan, and the University of Maryland are among the universities that have taken the lead in this area. ${ }^{16}$

\section{Today there are signs that more and more universities are recognizing the need to regularize conditions of employment for a professional "teaching corps."}

I will not attempt to describe in any detail the elements involved in professionalizing the teaching corps (which will, in any case, vary from institution to institution), but I do believe that they should include:

》 A well-formulated set of titles, plus compensation and benefits commensurate with contributions. Northwestern is experimenting with the title "Professor of Instruction."17

» A clear understanding of terms of appointment and opportunities for re-appointment. I do not think that conferring tenure is necessary or appropriate given needs to preserve staffing flexibility; there are other ways to protect the academic freedom of NTT faculty.

» A well-defined evaluation process that spells out basic protections (rights of appeal) for NTT faculty who must enjoy the core elements of academic freedom, such as the right to express one's own views on even the most controversial issues.

» Measures to confer dignity and respect on NTT faculty with, for example, the right to participate in faculty deliberations. The large set of NTT faculty should be regarded as within the mainstream of higher education, not as step-children.

\footnotetext{
${ }^{16}$ Bowen and Tobin, Locus of Authority, pp. $157 \mathrm{ff}$, contains references to evolving practice at these institutions as well as a historical discussion of the development of professional research staffs.

${ }^{17}$ See Colleen Flaherty, "Professors of Instruction," Inside Higher Ed, August 12, 2015. https://www.insidehighered.com/news/2015/08/12/northwestern-us-arts-and-sciences-college-updates-titles-teachingfaculty-and-offers.
} 


\section{Revisiting Shared Governance}

Last on my list of challenges for higher education is the need to rethink some - but by no means all - of the principles of shared governance that have been with us since the late $19^{\text {th }}$ century. To begin with what should not be changed: faculty must be relied on to vet the qualifications of their peers and we should resist vigorously efforts by others to decide who does and who does not have the qualifications for teaching/ research positions. Similarly, the core principle of academic freedom is that faculty should be expected to say and to write what they believe, without regard for the views of legislators, trustees, or fellow faculty members - provided that they follow the standards of responsible, professional, utterance that have been part of the academic freedom bargain for many years. (Here again, historical context is instructive.) Tenure is the bedrock protection of this right but it is by no means the only way to safeguard the freedom of utterance on which vigorous pursuit of truth depends-there are, for example, certainly ways of protecting the academic freedom of NTT faculty.

Faculty must be careful not to overreach, as there has been some tendency to do, especially since the late '60s and early 70s. History teaches us that it is a mistake to attempt to apply the principle of academic freedom to areas in which it does not belong, such as decisions as to overall staffing configurations. Administrators and trustees must be expected to make the hard financial/ educational choices that inevitably affect both the size and the composition of the teaching staff. As Frederick P. Schaffer, general counsel of CUNY, has explained well: "To link to academic freedom every policy and procedure that a professional association might want for its members is to drain the concept of all meaning...."18

Control over teaching methods is a key area in which faculty have much to contributeindeed their professional expertise and their enthusiasm are essential elements in the thoughtful pursuit of progress. But, to inject another historical note, as Gene Tobin and I argue in Locus of Authority: "it is time for individual faculty members to give up cheerfully, and not grudgingly, any claim to sole authority over teaching methods of all kinds."19 In exchange, faculty should be given an important seat at a bigger table, a table at which truly collaborative thinking is needed before administrators, armed with good faculty advice, exercise their responsibility for making decisions about the scale and nature of investments-judgments for which they need to be held accountable. Decisions also have to be made as to how to shape the export and import of new pedagogies across

${ }^{18}$ See Frederick Schaffer, A Guide to Academic Freedom," CUNY Bulletin, January 2, 2012.

${ }^{19}$ Bowen and Tobin, Locus of Authority, p. 173. 
institutions as well as across fields of study. Advances in technology make it imperative to move away from historical notions that departments must drive all decisions of this kind. Moving away from a vertical, departmental "silo," approach to resolving important questions will not be easy, but it is essential. We have to organize ourselves to think more horizontally.

\section{The right model of shared governance going forward is not "who owns what" (faculty versus administrators versus trustees), but how all parties can work together most effectively. "Shared governance" should not mean "divided governance."}

I know of no formulaic approach to cross-departmental decision-making that will apply in anything like all situations. It is evident, for example, that there are many complicated issues of IP rights and institutional responsibility for relationships with other institutions that wish to use parts or all of platforms/ content developed at university X. Some way of assuring continued access to what may seem like ephemeral content is important but very tricky. The J STOR model may be instructive. We are in the early stages of sorting out these issues. But one thing is clear, at least to me: the right model of shared governance going forward is not "who owns what" (faculty versus administrators versus trustees), but how all parties can work together most effectively. "Shared governance" should not mean "divided governance."

As a committed empirical "bean counter," I should be expected, and should expect myself, to have rigorous answers to many questions of this kind. But, true confession, I do not. In fact, I am driven to fall back on vague notions of trust and good will. Mindsets really matter. Brian Rosenberg, the very able president of Macalester College, has it right when he says: "Organizations with a culture of suspicion make decisions to avoid the worst, while those with a culture of trust make decisions to aspire to the best." 20

Trust, in turn, depends on a widely shared sense of educational mission and a commitment to advancing the important humanistic goals for which higher education has stood for generations. The cynicism of today notwithstanding, I believe that the great majority of faculty and administrators continue to believe strongly in what they do -

${ }^{20}$ Personal correspondence, July 2, 2014. 
which is why they came to the party in the first place. Otherwise, they would have chosen a different life path. What those of us in academia do really matters, as a reasonable dose of introspection should remind everyone who has benefitted so much from attending great institutions such as this one. We should be unabashedly proud of having chosen what is indeed a noble calling. 